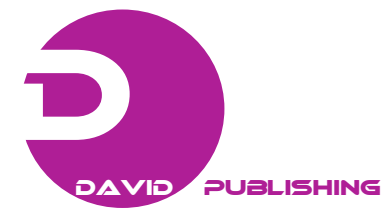

\title{
Exergetic Comparative Analysis of Ammonia and Carbon Dioxide Two-Stage Cycles for Simultaneous Cooling and Heating
}

\author{
Alexandru Dobrovicescu ${ }^{1}$, Alexandru Serban ${ }^{2}$, Ciprian Filipoiu ${ }^{1}$ and Liviu Drughean ${ }^{3}$ \\ 1. University Politehnica of Bucharest, Bucharest 060042, Romania \\ 2. Transilvanya University of Brasov, Brasov 500036, Romania \\ 3. Technical University of Civil Engineering, Bucharest 060042, Romania
}

Received: August 28, 2013 / Accepted: January 10, 2014 / Published: February 28, 2014.

\begin{abstract}
The paper deals with the comparative analysis of the performance of cooling and heating systems operating with $\mathrm{NH}_{3}$ (ammonia) or $\mathrm{CO}_{2}$ (carbon dioxide), both natural refrigerants. The study is based on the exergetic analysis that points out the location and the magnitude of a system malfunction. Both systems, with $\mathrm{NH}_{3}$ or $\mathrm{CO}_{2}$ operate in two stages. The exergetic analysis gives the direction of the structural optimization. The exergetic analysis has shown that the best structural schematic is not the same for the two agents. The exergetic analysis points out that the largest exergy destruction in the $\mathrm{CO}_{2}$ cycle is due to the throttling process and offers solutions to diminish it.
\end{abstract}

Key words: Exergetic analysis, cooling and heating systems, the two stage of refrigeration system, structural optimization.

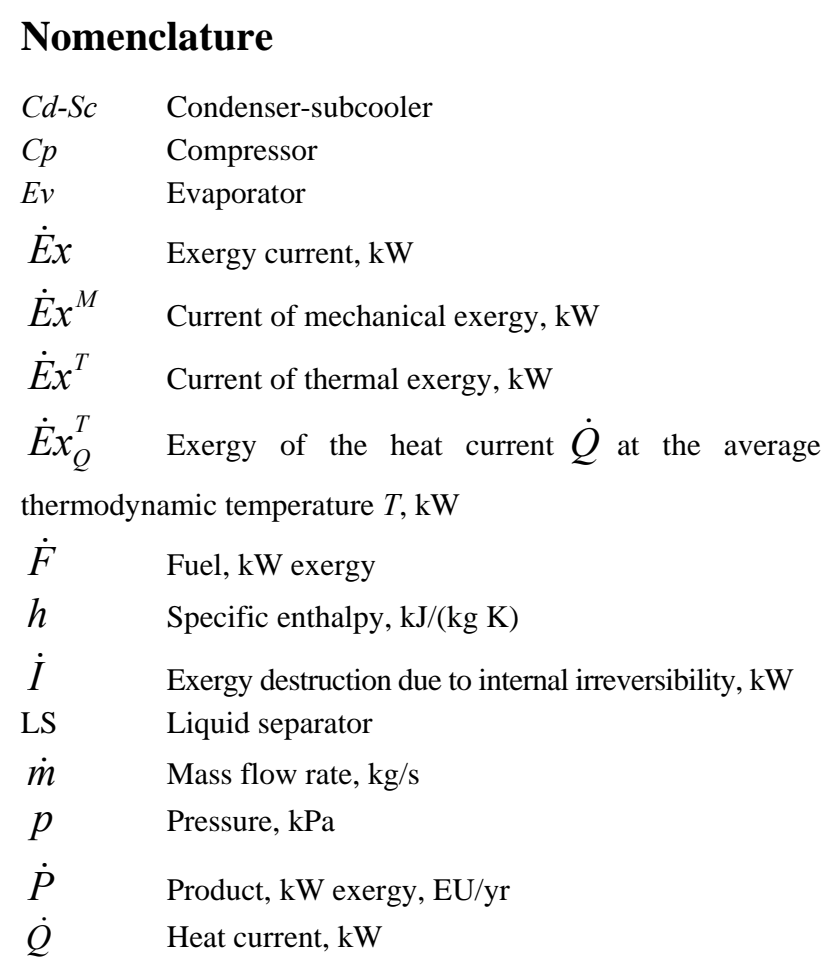

Corresponding author: Liviu Drughean, Ph.D., research field: applied thermal dynamics. E-mail: liviu.drughean@gmail.com.

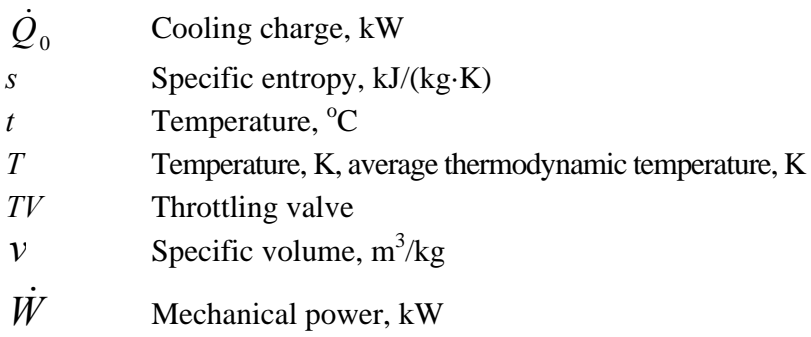

\section{Subscripts and superscripts}

c $\quad$ Condenser

cp Compressor

el Electrical

$f \quad$ Friction

$h \quad$ Heater

$i \quad$ Intermediary, inlet

$m \quad$ Mechanical

$o \quad$ Outlet

$P \quad$ Pump

$t \quad$ Total, throttling

$v \quad$ Evaporator

w Water

wi Water inlet

wo Water outlet 
$0 \quad$ Ambient parameter

$1 \quad$ First stage

2 Second stage

\section{Introduction}

Concerns for limiting the global warming phenomenon and the ozone depletion turned back the interest of the refrigeration industry towards the natural refrigerants $\mathrm{NH}_{3}$ and $\mathrm{CO}_{2}$ [1]. If ammonia, in spite of its very good thermodynamic properties does not match the requirements of safe refrigerant caused by toxicity and/or flammability, $\mathrm{CO}_{2}$ keeps the standard of safety refrigerant.

Ammonia has by far the highest COP (coefficient of performance) (Table 1) but for safety reasons carbon dioxide is preferred in commercial and large transport refrigeration.

The problem of low critical temperature of Carbone dioxide is overcome by operating the system in the transcritical region. Many researches reveal the good efficiency of $\mathrm{CO}_{2}$ when used in heat pumps for hot water heating $[2,3]$.

Carbon dioxide is characterized by environmental friendliness, low price, easy availability, non-flammability, non-toxicity, compatibility with various common materials and compactness due to high operating pressures.

This paper attempts to give some answers about the conduct of $\mathrm{CO}_{2}$ as refrigerant in systems for simultaneous cooling and heating in the aim of finding the best structure of the cycle.

To reveal the weaknesses of the $\mathrm{CO}_{2}$ systems comparatively with the ones operating with $\mathrm{NH}_{3}$, an exergetic analysis was carried on. The exergetic analysis is the only one capable to point out a malfunction intrinsically connected to a specific process. Moreover, the systems used for both refrigeration and heating offer two products represented by two quantities of heat-one received from the cold chamber and the other one transferred to the hot carrying agent. The two thermal energies have different temperature levels. Only the exergetic analysis that accounts for both the quantity of heat transferred and its temperature level in correlation with the ambient temperature can give the real measure of the system performance [4-6].

The comparative analysis of the exergy destruction and losses of the key pieces of the cooling and heating systems operating with $\mathrm{NH}_{3}$ and $\mathrm{CO}_{2}$ has revealed the weakness of each process due to the peculiar conduct of each one of the two refrigerants. Such a study done by Cavallini and Neksa [7] on a refrigeration system with $\mathrm{CO}_{2}$ clearly shows that for this agent throttling is the most penalizing process.

In the present paper three schematics of two-stage refrigeration cycles have been analysed: a two-stage system with incomplete intermediary cooling, a twostage system with intercooling by the injection of a cold stream and a two-stage system with flash intercooling.

The comparative exergetic analysis performed on these different two-stage refrigeration cycles operating with $\mathrm{CO}_{2}$ and $\mathrm{NH}_{3}$ has shown that the best structural schematic is not the same for the two agents.

\section{Schematic of a Two-Stage System with Incomplete Intermediary Cooling}

The constructive and operating characteristics of the system (Figs. 1 and 2) are: The cold carrying agent is water that is cooled in the evaporator from $t_{v, w i}=$ $15^{\circ} \mathrm{C}$ to $t_{v, w o}=8^{\circ} \mathrm{C}$, the heat carrying agent is water whose temperature increases from $t_{c, w i}=45^{\circ} \mathrm{C}$ to $t_{c, w o}$ $=55^{\circ} \mathrm{C}$, the ambient temperature is $t_{0}=25{ }^{\circ} \mathrm{C}$, the isentropic, mechanic and electric efficiencies of compressors and water pumps for NH3 are respectively $\eta_{s}=0.8, \eta_{m}=0.83$ and $\eta_{e l}=0.9$. For $\mathrm{CO}_{2}$ the isentropic efficiency of the compression process has been calculated with the correlation $\eta_{s, c p}=0.9343-0.04478 \cdot \pi_{s t}$ [8].

The $\mathrm{NH}_{3}$ system is provided with a flash evaporator (Fig. 1) while the $\mathrm{CO}_{2}$ one operates with direct expansion evaporator and an internal subcooler-superheater (Fig. 2). 
Table 1 Thermodynamic properties of the natural refrigerants $\mathrm{NH}_{3}$ and $\mathrm{CO}_{2}$.

\begin{tabular}{lllllll}
\hline Substance & Refrigerant & $\begin{array}{l}\text { Normal boiling } \\
\text { temperature }\left({ }^{\circ} \mathrm{C}\right)\end{array}$ & $\begin{array}{l}\text { Critical point } \\
\left({ }^{\circ} \mathrm{C}\right)\end{array}$ & ODP & GWP & $\begin{array}{l}\text { COP } \\
-15 / 30\left({ }^{\circ} \mathrm{C}\right)\end{array}$ \\
\hline Carbon dioxide & $\mathrm{R}-744$ & -55.6 & 31.0 & 0 & 1 & 2.56 \\
Ammonia & $\mathrm{R}-717$ & -33.3 & 135.0 & 0 & 0 & 4.76 \\
\hline
\end{tabular}

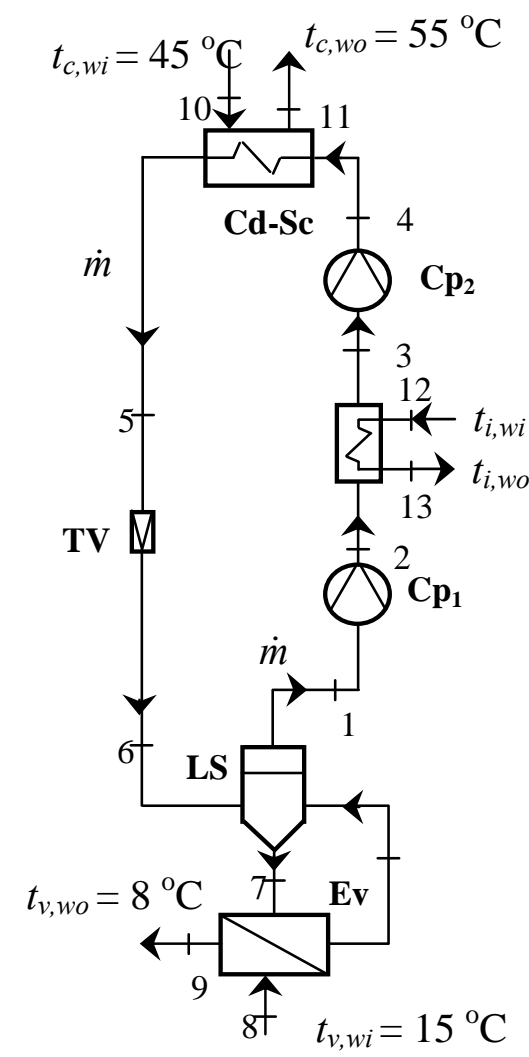

Fig. $1 \mathrm{NH}_{3}$ system with intermediary cooling performed by the environmental medium.

\subsection{Exergetic Analysis}

The two-stage refrigeration system offers to the customers two products-The exergy of the refrigerating power at the temperature level of the cold carrying agent $\left|\dot{\mathrm{Ex}}_{\mathrm{Qv}}^{\mathrm{T}_{\mathrm{V}} \mathrm{w}}\right|$ and the exergy of the thermal power at the temperature level of the heat carrying agent $\left|\dot{\mathrm{Ex}}_{\mathrm{Qc}}^{\mathrm{T}_{\mathrm{C}, \mathrm{w}}}\right|$.

For the cooling process realized in the evaporator the Product and the Fuel of this operating zone are respectively (Fig. 1):

$$
\dot{P}_{v}=\dot{E} x_{9}^{T}-\dot{E} x_{8}^{T}=\dot{m}_{v, w} \cdot c_{v, w}\left[\left(t_{9}-t_{8}\right)-T_{0} \ln \frac{T_{9}}{T_{8}}\right](1)
$$

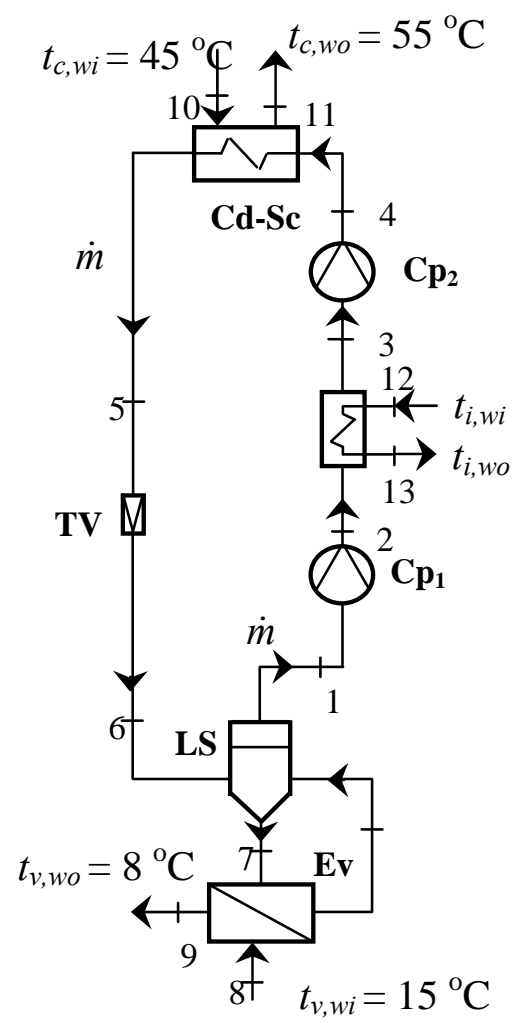

Fig. $2 \mathrm{CO}_{2}$ system with intermediary cooling performed by the environmental medium.

$$
\begin{aligned}
& \dot{F}_{v}=\left(\dot{E} x_{6}^{T O T}-\dot{E} x_{1}^{T O T}\right)+\left(\dot{E} x_{8}^{M}-\dot{E} x_{9}^{M}\right)= \\
& \dot{m}\left[h_{6}-h_{1}-T_{0}\left(s_{6}-s_{1}\right)\right]+\frac{\dot{m}_{v, w} \cdot v_{v, w} \cdot\left|\Delta p_{v}\right|}{\eta_{s} \cdot \eta_{m} \cdot \eta_{e l}}
\end{aligned}
$$

The fuel consists of the total exergy ( $\dot{\mathrm{Ex}}_{\mathrm{x}}^{\mathrm{TOT}}$ ) consumed on the refrigerant side $\left(\mathrm{NH}_{3}\right.$ or $\left.\mathrm{CO}_{2}\right)$ to which the mechanical exergy consumed by the pump that runs the cold carrying agent is added [9]. For the evaporator, besides the fact that nothing from the power consumed by the pump to run the cold carrying agent is recovered, in addition, the heat generated by friction and taken away by the cold carrying agent represents a destruction that the compressors of the system have to supplementary compensate.

The exergy destruction due to pressure loss in the evaporator is: 


$$
\dot{I}_{v, f}=\frac{\dot{m}_{v, w} \cdot v_{v, w} \cdot\left|\Delta p_{v}\right|}{\eta_{s}}+\frac{\dot{m}_{v, w} \cdot v_{v, w} \cdot\left|\Delta p_{v}\right|}{\eta_{s}}\left(\frac{T_{0}}{T_{v, w}}-1\right) \text { (3) }
$$

The irreversibility of the heat transfer at a finite temperature difference in the evaporator leads to the exergy destruction:

$$
\dot{I}_{v, \Delta T}=\dot{Q}_{01} \cdot T_{0} \frac{T_{v, w}-T_{v}}{T_{v, w} \cdot T_{v}}
$$

For the heater (condenser for $\mathrm{NH}_{3}$ ) the product is represented by the increase in the thermal exergy of the heat carrying agent (Fig. 1):

$$
\begin{gathered}
\dot{P}_{c d}=\dot{E} x_{11}^{T}-\dot{E} x_{10}^{T}=\dot{m}_{c, w} \cdot c_{c, w}\left[\left(t_{11}-t_{10}\right)-T_{0} \ln \frac{T_{11}}{T_{10}}\right](5) \\
\dot{F}_{c d}=\left(\dot{E} x_{4}^{T O T}-\dot{E} x_{5}^{T O T}\right)+\left(\dot{E} x_{10}^{M}-\dot{E} x_{11}^{M}\right)= \\
\dot{m}_{2}\left[h_{4}-h_{5}-T_{0}\left(s_{4}-s_{5}\right)\right]+\dot{m}_{c, w} \frac{v_{c, w} \cdot\left|\Delta p_{c}\right|}{\eta_{s} \cdot \eta_{m} \cdot \eta_{e l}}
\end{gathered}
$$

The exergy destruction in the heater is represented by :

$$
\dot{I}_{c d}=\dot{I}_{c d, f}+\dot{I}_{c d, \Delta T}
$$

Where:

$$
\dot{I}_{c d, f}=T_{0} \frac{\dot{m}_{c, w} \cdot v_{c, w} \cdot\left|\Delta p_{h}\right|}{\eta_{s} \cdot T_{c, w}}
$$

And:

$$
\dot{I}_{c d, \Delta T}=\dot{Q}_{c d} \cdot T_{0} \frac{T_{c}-T_{c, w}}{T_{c} \cdot T_{c, w}}
$$

Denoting by $\dot{W}_{c p, t}$ and $\dot{W}_{P, t}$ the mechanical powers consumed by the system compressors and pumps - the exergetic balance equation on the customer side becomes (Fig. 1):

$$
\begin{aligned}
& \left|\dot{W}_{c p 1, t}\right|+\left|\dot{W}_{c p 2, t}\right|+\left|\dot{W}_{P 1, t}\right|+\left|\dot{W}_{P 2, t}\right|= \\
& \left(\dot{E} x_{9}^{T}-\dot{E} x_{8}^{T}\right)+\left(\dot{E} x_{11}^{T}-\dot{E} x_{10}^{T}\right)+ \\
& +\dot{I}_{c p 1}+\dot{L}_{c p 1, m, e l}+\dot{I}_{c p 2}+\dot{L}_{c p 2, m, e l}+\dot{I}_{c d, f}+ \\
& +\dot{I}_{c d, \Delta T}+\dot{L}_{c d, P}+\dot{I}_{t 1}+\dot{I}_{v, \Delta T}+\dot{I}_{v, f}+\dot{L}_{v, P}
\end{aligned}
$$

The exergetic efficiency is:

$$
\begin{gathered}
\eta_{e x}=\frac{\Delta \dot{E} x_{v}^{T}+\Delta \dot{E} x_{c}^{T}}{\sum \dot{W}_{t}} ; \eta_{e x, e v}=\frac{\dot{P}_{v}}{\dot{F}_{v}} ; \\
\eta_{e x, c d(g h)}=\frac{\dot{P}_{c d}}{\dot{F}_{c d}}
\end{gathered}
$$

\subsection{Influence of the Variation of the Operating Parameters}

The project states the refrigeration power and the temperature levels at which cold and heat are supplied to the customers.

The intermediary pressure of the two-stage system will be stated based on the maximum efficiency criterion.

For the refrigeration and heat pump systems presented in Figs. 1 and 2, the temperatures in the key states of the cycles, the mass flow rates and the energy rates per $1 \mathrm{~kW}$ of cold are shown in Tables 2 and 3 .

For both $\mathrm{NH}_{3}$ and $\mathrm{CO}_{2}$ cycles, temperature $t_{2}$ at the discharge from the first stage compressor strongly recommends using the intercooler as well, for heating the thermal agent. The overall efficiency of the cycle increases in this way.

While for $\mathrm{CO}_{2}$ temperatures at the discharge from compressors cause no problem, for $\mathrm{NH}_{3}$ the second stage compressor operates at the highest avoidable temperature limit.

Figs. 3 and 4 present the variation of the overall exergy efficiency and of the compression ratio in the first stage against the intermediary pressure for the two compared refrigeration systems.

In both cases, the lower is the intermediary pressure, with respect to the $\mathrm{NH}_{3}$ system for the temperature limit in the discharge of the second stage compressor, the higher is the exergetic efficiency. In spite of the large operating pressures for the $\mathrm{CO}_{2}$ system, the first stage compression ratio is approximately twice lower than for the $\mathrm{NH}_{3}$ system leading for $\mathrm{CO}_{2}$ to low mechanical work input.

The lower exergetic efficiency for $\mathrm{CO}_{2}$ compared to the $\mathrm{NH}_{3}$ system is due to higher exergy destructions.

The comparative analysis for the $\mathrm{NH}_{3}$ and $\mathrm{CO}_{2}$ systems (Figs. 5 and 6) reveals a three times higher exergy destruction ratio with throttling for $\mathrm{CO}_{2}$. The large exergy destruction with throttling explains the lower exergetic efficiency for the $\mathrm{CO}_{2}$ system compared with the $\mathrm{NH}_{3}$ one. 
Table $2 \mathrm{NH}_{3}$ system. Temperatures, mass flow rates and energy rates per $1 \mathrm{~kW}$ of cold (Fig. 1).

\begin{tabular}{llllll}
\hline $\begin{array}{l}\mathrm{p}_{\text {int }} \\
\text { (bar) }\end{array}$ & $\begin{array}{l}\dot{m} \cdot 10^{3} \\
(\mathrm{~kg} / \mathrm{s}) / \mathrm{kW} \text { cold })\end{array}$ & $\begin{array}{l}\dot{W}_{c p, t} \\
(\mathrm{~kW} / \mathrm{kW} \text { cold })\end{array}$ & $\begin{array}{l}\dot{Q}_{c d}+\dot{Q} \text { int } c \\
(\mathrm{~kW} / \mathrm{kW} \text { cold })\end{array}$ & $\begin{array}{l}t_{2} \\
\left({ }^{\circ} \mathrm{C}\right)\end{array}$ & $\begin{array}{l}t_{4} \\
\left({ }^{\circ} \mathrm{C}\right)\end{array}$ \\
\hline 10 & 1.0002 & 0.4063 & 1.4063 & 60.53 & 130.2 \\
12 & 1.0002 & 0.4112 & 1.4112 & 76.87 & 131.7 \\
14 & 1.0002 & 0.4144 & 1.4144 & 91.17 & 132.57 \\
\hline
\end{tabular}

Table $3 \mathrm{CO}_{2}$ system. Temperatures, mass flow rates and energy rates per $1 \mathrm{~kW}$ of cold (Fig. 2).

\begin{tabular}{llllll}
\hline $\begin{array}{l}\mathrm{p}_{\text {int }} \\
{[\mathrm{bar}]}\end{array}$ & $\begin{array}{l}\dot{m} \cdot 10^{3} \\
(\mathrm{~kg} / \mathrm{s}) / \mathrm{kWcold})\end{array}$ & $\begin{array}{l}\dot{W}_{c p, t} \\
(\mathrm{~kW} / \mathrm{kW} \text { cold })\end{array}$ & $\begin{array}{l}\dot{Q}_{h}+\dot{Q} \text { int } c \\
(\mathrm{~kW} / \mathrm{kW} \text { cold })\end{array}$ & $\begin{array}{l}t_{2} \\
\left({ }^{\circ} \mathrm{C}\right)\end{array}$ & $\begin{array}{l}t_{4} \\
\left({ }^{\circ} \mathrm{C}\right)\end{array}$ \\
\hline 65 & 8.511 & 0.7573 & 1.7573 & 75.2 & 114.4 \\
70 & 8.511 & 0.7652 & 1.7652 & 82.03 & 114.9 \\
75 & 8.511 & 0.7738 & 1.7738 & 88.52 & 115.3 \\
\hline
\end{tabular}

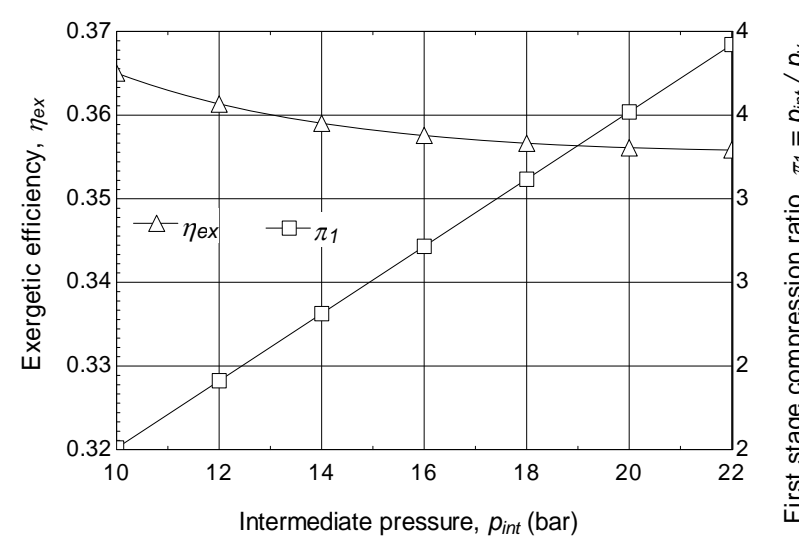

Fig. $3 \mathrm{NH}_{3}$ system. Variation of the exergetic efficiency and of compression ratio in the first stage against the intermediary pressure in schematic Fig. 1.

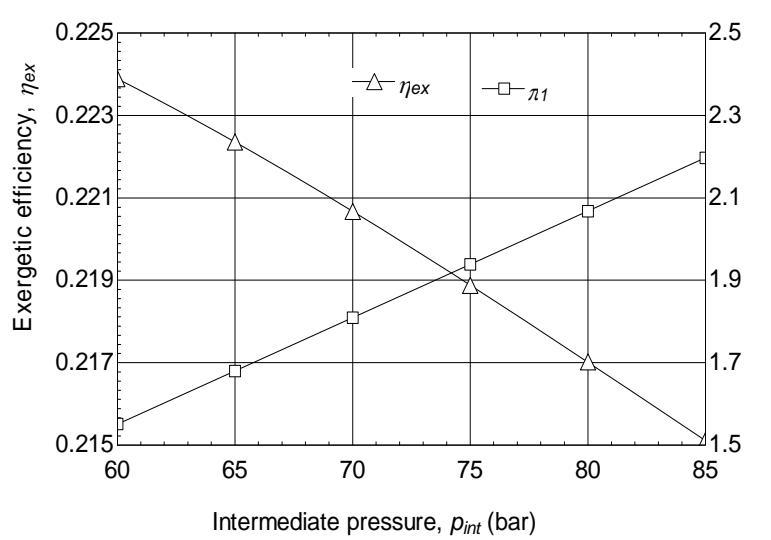

Fig. $4 \mathrm{CO}_{2}$ system. Variation of the exergetic efficiency and of compression ratio in the first stage against the intermediary pressure in schematic Fig. 2.

Another larger exergy destruction ratio that leads to lower exergetic efficiency for $\mathrm{CO}_{2}$ than $\mathrm{NH}_{3}$ is in the gas heater. This characteristic recommends $\mathrm{CO}_{2}$ for heating at higher temperatures, i.e., hot water.

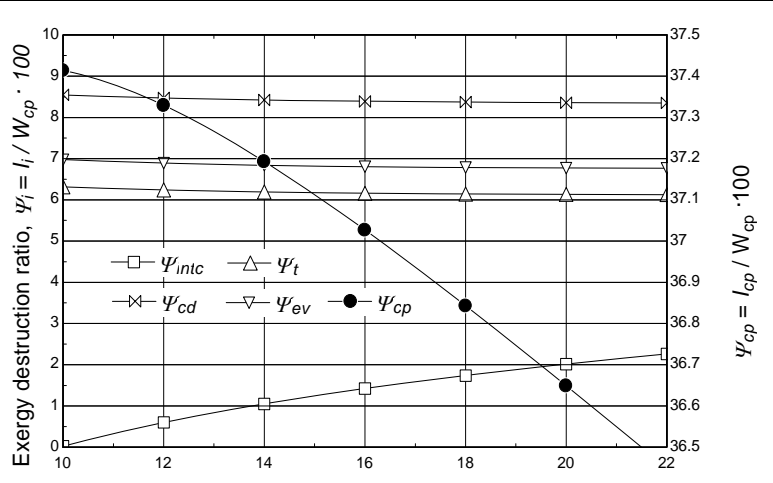

Intermediate pressure, $p_{\text {int }}$ (bar)

Fig. $5 \mathbf{N H}_{3}$ system. Exergy destruction ratio related to the exergy of the total plant fuel against the intermediary pressure in schematic Fig. 1.

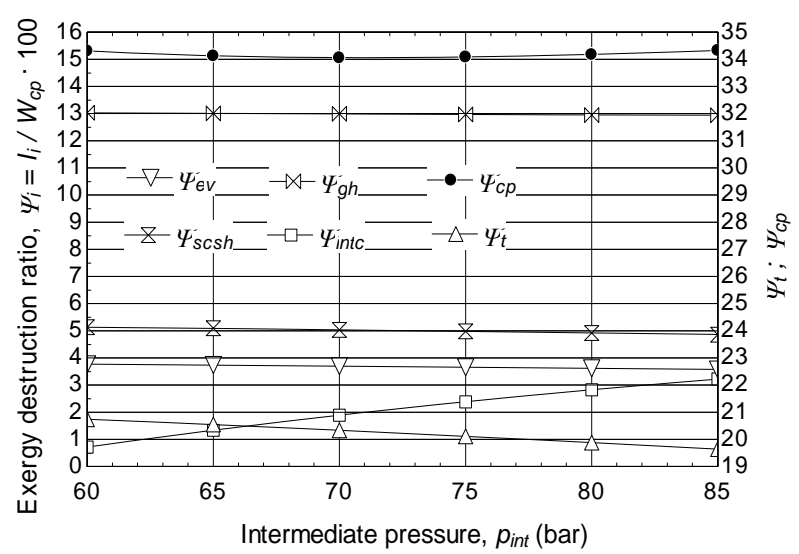

Fig. $6 \mathrm{CO}_{2}$ system. Exergy destruction ratio related to the exergy of the total plant fuel against the intermediary pressure in schematic Fig. 2.

As expected, the lower compression ratio in the first stage for $\mathrm{CO}_{2}$ is accompanied by the lower exergy destruction ratio in the compressor, compared to $\mathrm{NH}_{3}$ (Figs. 5 and 6). 
In Figs. 7 and 8, the behaviour of the exergetic efficiency of the overall cycle, of the evaporate and of the condenser or gas heater is presented at the variation of the evaporator pressure drop.

For both systems the pressure drop in the evaporator has the same influence on the exergetic efficiency of the evaporator (Figs. 7 and 8).

3. Schematic of a Two-Stage System with Intermediary Cooling Performed by the Injection of a Cold Stream in the First Stage Discharged Gas

To diminish the temperature of the gas at the discharge from the high pressure compressor and to reduce in this way the accompanying exergy destruction due to heat transfer at a high temperature difference in the heater, the intermediary cooling is performed by the injection of a cold stream in the compressed gas between the two stages (Figs. 9 and 10).

For the flow charts presented in Figs. 9 and 10 the temperatures in the key states of the cycles, the mass flow rates and the energy rates per $1 \mathrm{~kW}$ of cold are shown in Tables 4 and 5.

The intermediary cooling performed by the injection of a cold stream leads for both agents to a decrease in the discharge temperature from the second stage compressor. For both agents the exergy destruction due to heat transfer at a finite temperature difference in the heater is expected to diminish. For $\mathrm{CO}_{2}$ the quantity of heat transferred to the thermal agent increases (Tables 4 and 5).

For $\mathrm{NH}_{3}$, the overall exergetic efficiency remains practically unchanged, while for $\mathrm{CO}_{2}$, it decreases (Figs. 11 and 12).

The exergy destructions related to the total input power are presented in Figs. 13 and 14. The decrease in the exergetic efficiency of the $\mathrm{CO}_{2}$ cycle is due to the rapid increase in the exergy destruction ratio of the throttling process (Fig. 14).

Compared to the schematic given in Fig. 1 characterized by a single throttling process, in the present case (Fig. 10) the cycle operates with two throttlings.

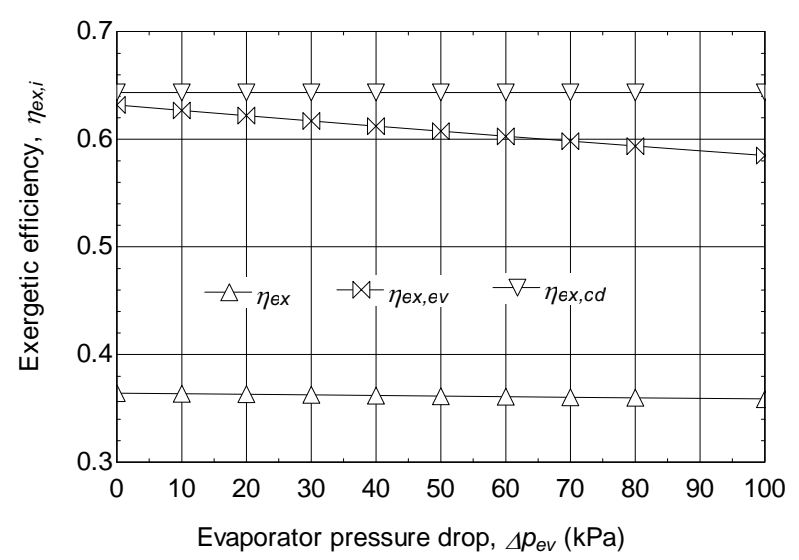

Fig. $7 \mathrm{NH}_{3}$ system. Variation of the exergetic efficiency against the pressure drop in the evaporator Fig. 1.

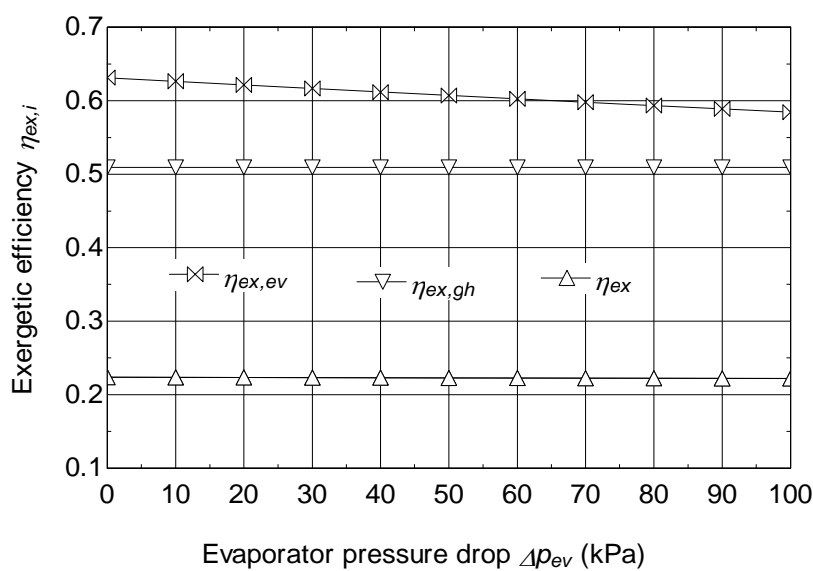

Fig. $8 \mathbf{N H}_{3}$ system. Variation of the exergetic efficiency against the pressure drop in the evaporator Fig. 2.

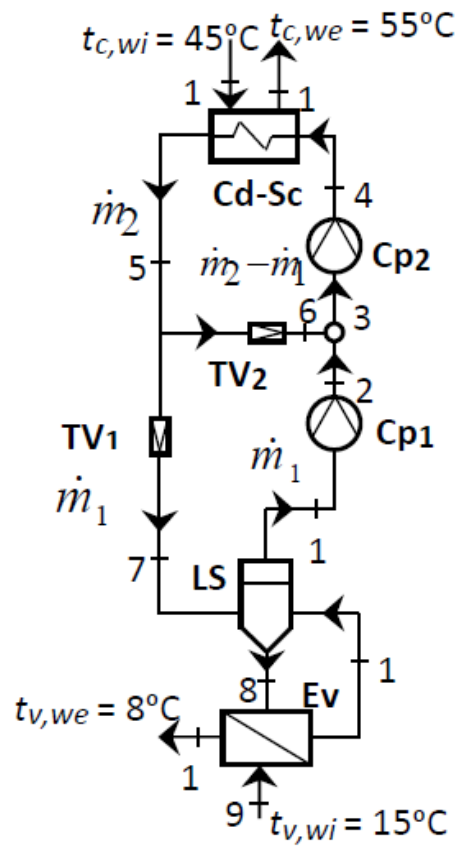

Fig. $9 \mathrm{NH}_{3}$ system with intermediary cooling achieved by the injection of a cold stream. 


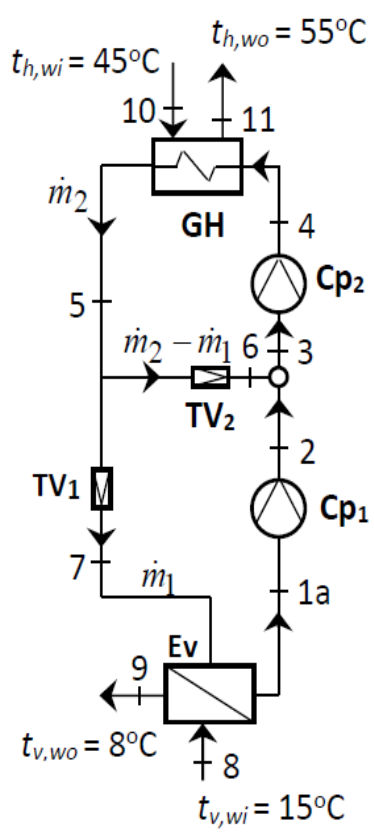

Fig. $10 \mathrm{CO}_{2}$ system with intermediary cooling achieved by the injection of a cold stream.
As expected, for $\mathrm{CO}_{2}$, the exergy destruction ratio in the heater due to the intermediary cooling by the injection of a cold stream (Fig. 10) is lower than the one corresponding to schematic presented in Fig. 1 (Fig. 14).

\section{Schematic of a Two-Stage System With Flash Intercooling}

To continue to diminish the exergy destruction a schematic with flash intercooling is proposed (Figs. 15 and 16).

For the flow charts presented in Figs. 15 and 16, the temperatures in the key states of the cycles, the mass flow rates and the energy rates per $1 \mathrm{~kW}$ of cold are shown in Tables 4 and 5.

For $\mathrm{NH}_{3}$ the exergetic efficiency has increased substantially (Fig. 17). This fact is due to the decrease

Table $4 \mathrm{NH}_{3}$ system. Temperatures, mass flow rates and energy rates per $1 \mathrm{~kW}$ of cold (Fig. 9).

\begin{tabular}{lllllll}
\hline $\begin{array}{l}\text { pint } \\
\text { (bar) }\end{array}$ & $\begin{array}{l}\dot{\mathrm{m}}_{1} \cdot 10^{3} \\
((\mathrm{~kg} / \mathrm{s}) / \mathrm{kWcold})\end{array}$ & $\begin{array}{l}\dot{\mathrm{m}}_{2} \cdot 10^{3} \\
((\mathrm{~kg} / \mathrm{s}) / \mathrm{kW} \text { cold })\end{array}$ & $\begin{array}{l}\dot{\mathrm{W}}_{\mathrm{cp}, \mathrm{t}} \\
(\mathrm{kW} / \mathrm{kW} \text { cold })\end{array}$ & $\begin{array}{l}\dot{\mathrm{Q}}_{\mathrm{cd}} \\
(\mathrm{kW} / \mathrm{kW} \text { cold })\end{array}$ & $\begin{array}{l}t_{2} \\
\left({ }^{\circ} \mathrm{C}\right)\end{array}$ & $\begin{array}{l}t_{4} \\
\left({ }^{\circ} \mathrm{C}\right)\end{array}$ \\
\hline 10 & 1.0002 & 1.083 & 0.413 & 1.413 & 60.53 & 115.90 \\
12 & 1.0002 & 1.111 & 0.4112 & 1.412 & 76.87 & 105.02 \\
14 & 1.0002 & 1.137 & 0.4144 & 1.412 & 91.17 & 96.23 \\
\hline
\end{tabular}

Table $5 \mathrm{CO}_{2}$ system. Temperatures, mass flow rates and energy rates per $1 \mathrm{~kW}$ of cold (Fig. 10).

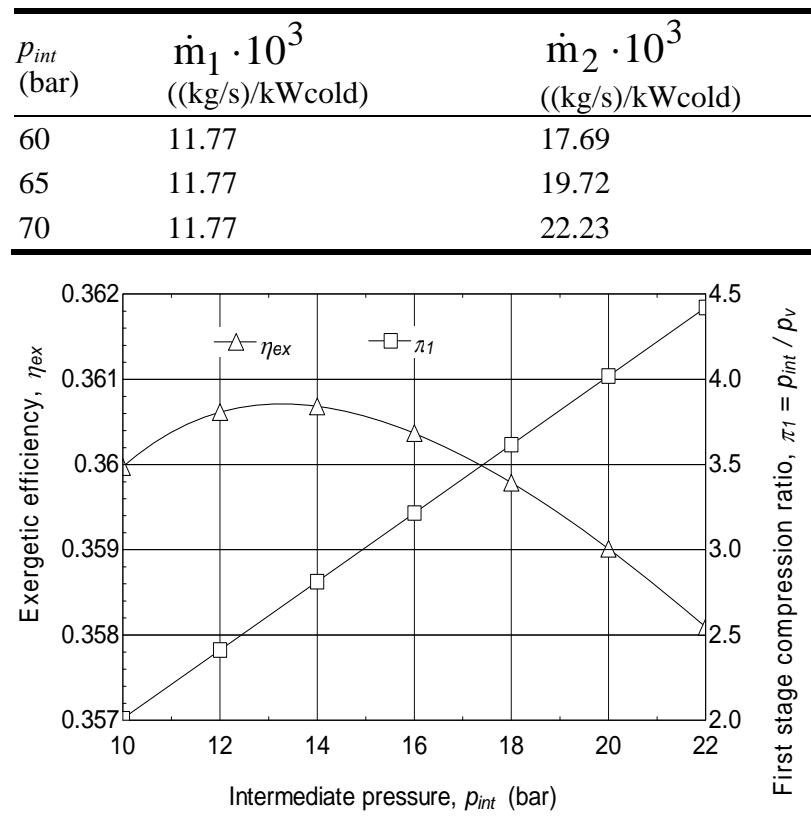

Fig. $11 \mathrm{NH}_{3}$ system. Variation of the exergetic efficiency and of the first stage compression ratio against the intermediary pressure for schematic Fig. 9.

\begin{tabular}{llll}
$\begin{array}{l}\dot{\mathrm{W}}_{\mathrm{cp}, \mathrm{t}} \\
(\mathrm{kW} / \mathrm{kW} \text { cold })\end{array}$ & $\begin{array}{l}\dot{\mathrm{Q}}_{\mathrm{h}} \\
(\mathrm{kW} / \mathrm{kW} \text { cold })\end{array}$ & $\begin{array}{l}t_{2} \\
\left({ }^{\circ} \mathrm{C}\right)\end{array}$ & $\begin{array}{l}t_{4} \\
\left({ }^{\circ} \mathrm{C}\right)\end{array}$ \\
\hline 1.068 & 2.068 & 43.31 & 85.52 \\
1.090 & 2.090 & 50.01 & 81.31 \\
1.115 & 2.115 & 56.34 & 77.49 \\
\hline
\end{tabular}

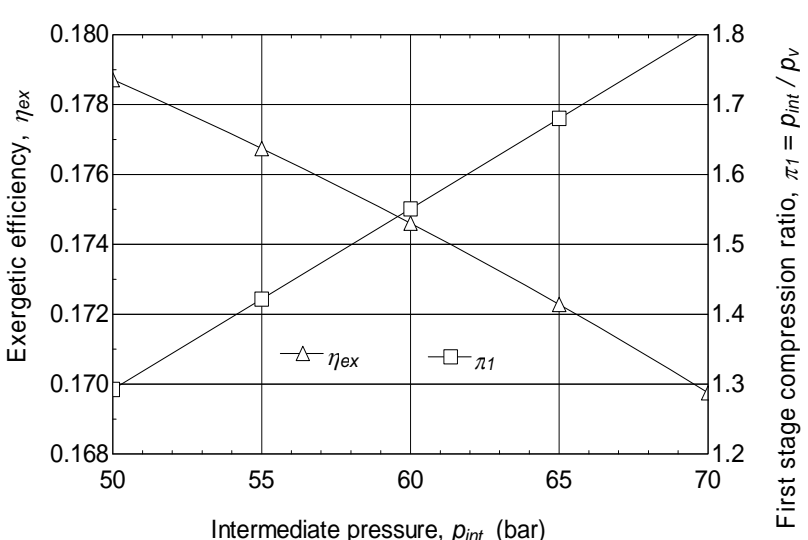

Fig. $12 \mathrm{CO}_{2}$ system. Variation of the exergetic efficiency and of the first stage compression ratio against the intermediary pressure for schematic Fig. 10. 

Cycles for Simultaneous Cooling and Heating

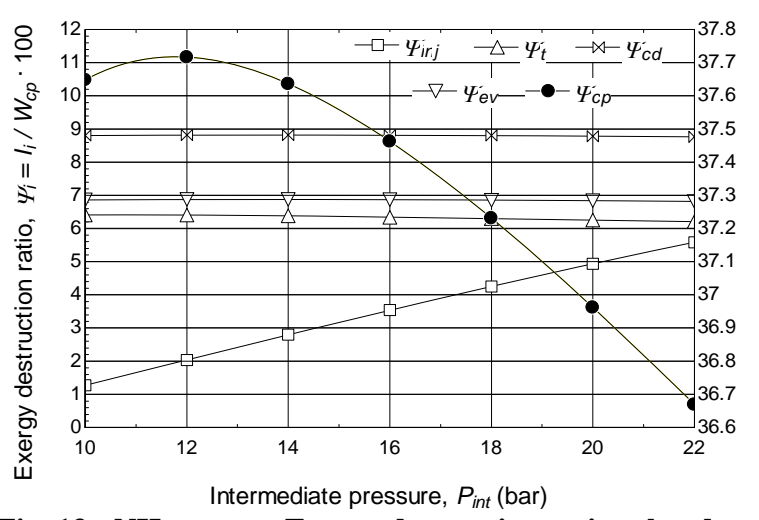

Fig. $13 \mathrm{NH}_{3}$ system. Exergy destruction ratio related to the exergy of the total plant fuel against the intermediary pressure for schematic Fig. 9.

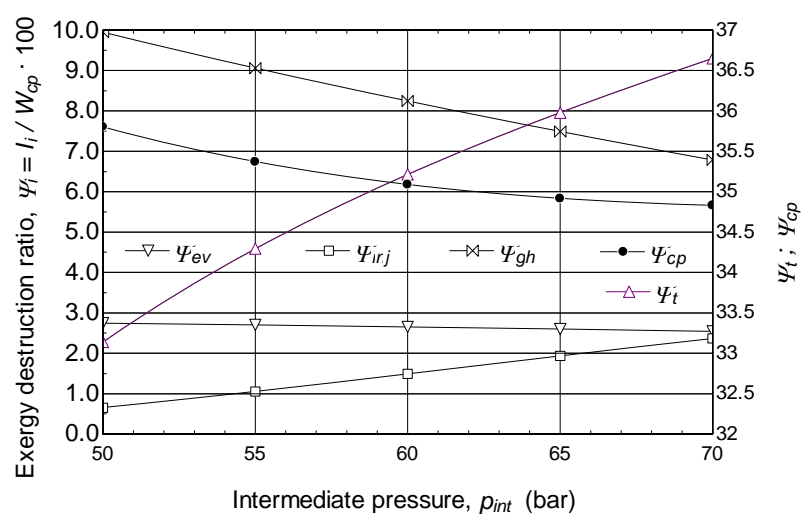

Fig. $14 \mathrm{CO}_{2}$ system. Exergy destruction ratio related to the exergy of the total plant fuel against the intermediary pressure for schematic Fig. 10.

Table $6 \mathrm{NH}_{3}$ system. Temperatures, mass flow rates and energy rates per $1 \mathrm{~kW}$ of cold (Fig. 15).

\begin{tabular}{lllllll}
\hline $\begin{array}{l}p_{\text {int }} \\
\text { (bar) }\end{array}$ & $\begin{array}{l}\dot{m}_{1} \cdot 10^{3} \\
((\mathrm{~kg} / \mathrm{s}) / \mathrm{kW} \text { cold })\end{array}$ & $\begin{array}{l}\dot{\mathrm{m}}_{2} \cdot 10^{3} \\
((\mathrm{~kg} / \mathrm{s}) / \mathrm{kW} \text { cold })\end{array}$ & $\begin{array}{l}\dot{\mathrm{W}}_{\mathrm{cp}, \mathrm{t}} \\
(\mathrm{kW} / \mathrm{kW} \text { cold })\end{array}$ & $\begin{array}{l}\dot{\mathrm{Q}}_{\mathrm{cd}} \\
(\mathrm{kW} / \mathrm{kW} \text { cold })\end{array}$ & $\begin{array}{l}t_{2} \\
\left({ }^{\circ} \mathrm{C}\right)\end{array}$ & $\begin{array}{l}t_{4} \\
\left({ }^{\circ} \mathrm{C}\right)\end{array}$ \\
\hline 10 & 0.87 & 1.084 & 0.386 & 1.386 & 60.52 & 108.88 \\
12 & 0.89 & 1.113 & 0.385 & 1.385 & 76.87 & 98.37 \\
14 & 0.91 & 1.14 & 0.387 & 1.387 & 91.17 & 89.91 \\
\hline
\end{tabular}

Table $7 \mathrm{CO}_{2}$ system. Temperatures, mass flow rates and energy rates per $1 \mathrm{~kW}$ of cold (Fig. 16).

\begin{tabular}{lllllll}
\hline $\begin{array}{l}p_{\text {int }} \\
\text { (bar) }\end{array}$ & $\begin{array}{l}\dot{m}_{1} \cdot 10^{3} \\
((\mathrm{~kg} / \mathrm{s}) / \mathrm{kWcold})\end{array}$ & $\begin{array}{l}\dot{\mathrm{m}}_{2} \cdot 10^{3} \\
((\mathrm{~kg} / \mathrm{s}) / \mathrm{kWcold})\end{array}$ & $\begin{array}{l}\dot{\mathrm{W}}_{\mathrm{cp}, \mathrm{t}} \\
(\mathrm{kW} / \mathrm{kW} \text { cold })\end{array}$ & $\begin{array}{l}\dot{\mathrm{Q}}_{\mathrm{h}} \\
(\mathrm{kW} / \mathrm{kW} \text { cold })\end{array}$ & $\begin{array}{l}t 2 \\
\left({ }^{\circ} \mathrm{C}\right)\end{array}$ & $\begin{array}{l}t 4 \\
\left({ }^{\circ} \mathrm{C}\right)\end{array}$ \\
\hline 60 & 5.71 & 22.04 & 1.068 & 1.97 & 43.31 & 75.92 \\
65 & 6.19 & 28.65 & 1.090 & 2.061 & 50.01 & 70.56 \\
70 & 6.9 & 48.62 & 1.115 & 2.397 & 56.34 & 64.66 \\
\hline
\end{tabular}

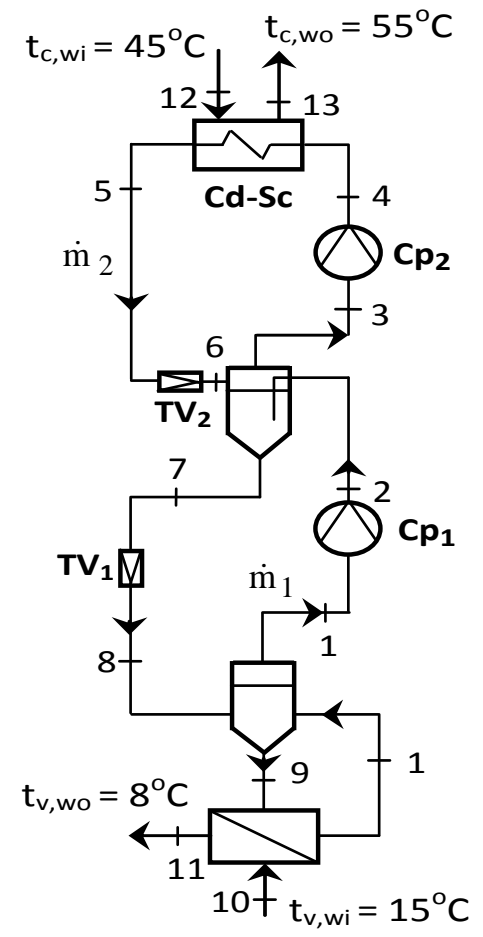

Fig. $15 \mathrm{NH}_{3}$ system with flash intercooling.

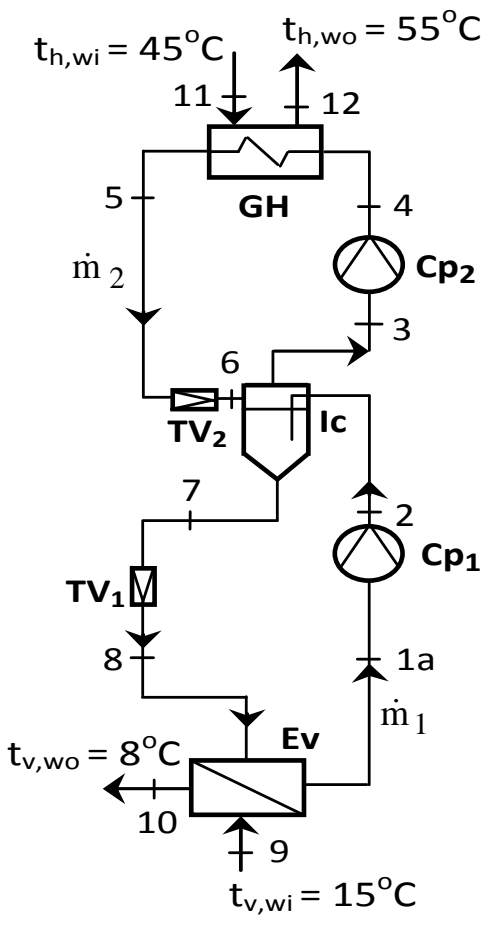

Fig. $16 \mathrm{CO}_{2}$ system with flash intercooling. 

Cycles for Simultaneous Cooling and Heating

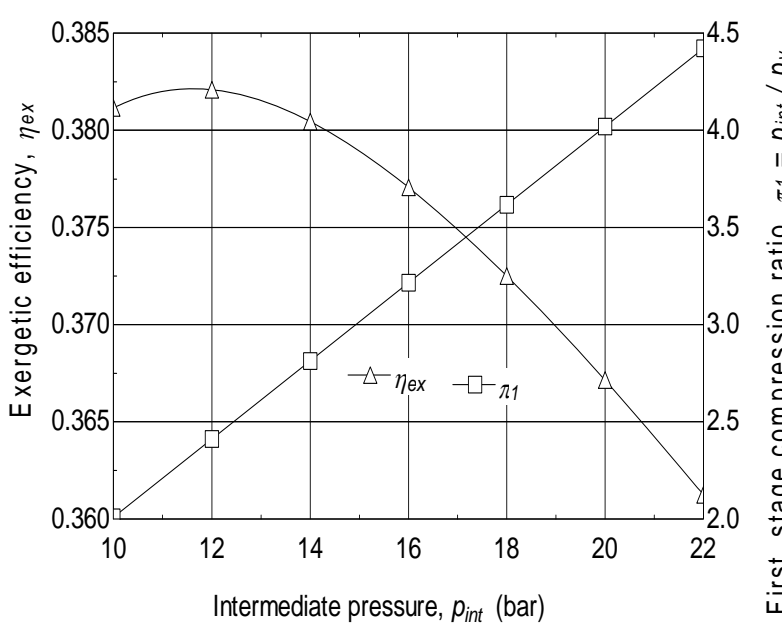

Fig $17 \mathrm{NH}_{3}$ system. Variation of the exergetic efficiency and of the first stage compression ratio against the intermediary pressure for schematic Fig. 15.

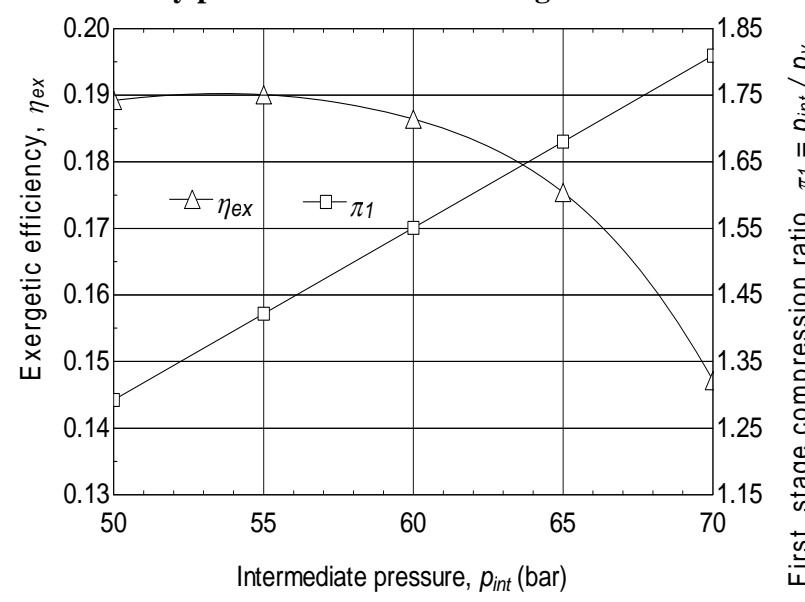

Fig. $18 \mathrm{CO}_{2}$ system. Variation of the exergetic efficiency and of the first stage compression ratio against the intermediary pressure for schematic Fig. 16.

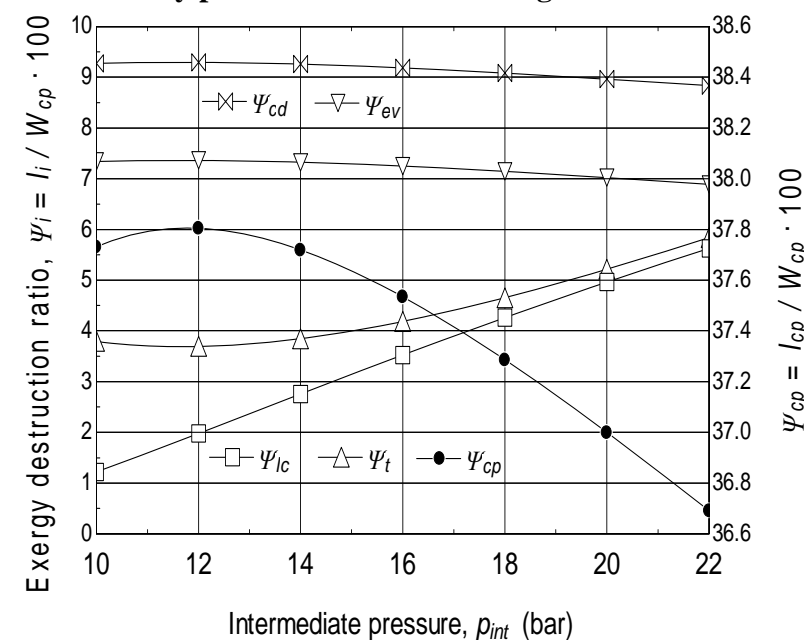

Fig. $19 \mathrm{NH}_{3}$ System. Exergy destruction ratio related to the exergy of the total plant fuel against the intermediary pressure for schematic Fig. 15.

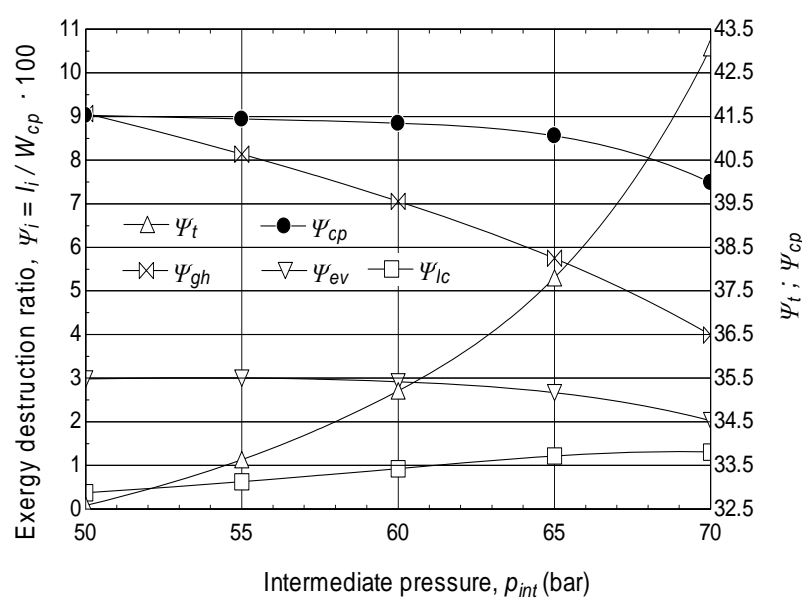

Fig. $20 \mathrm{CO}_{2}$ system. Exergy destruction ratio related to the exergy of the total plant fuel against the intermediary pressure for schematic Fig. 16.

in the total exergy destruction associated with throttling (Fig. 19).

For $\mathrm{CO}_{2}$ the overall exergetic efficiency increases comparatively with the flash gas by-pass intercooling (Figs. 12 and 18) but remains inferior to the efficiency corresponding to the incomplete intermediary cooling (Figs. 6 and 18). The slight increase in the exergetic efficiency is mainly due to the decrease in the exergy destruction in the gas heater (Figs. 14 and 20).

\section{Conclusions}

The exergetic analysis is the only method capable to rate the performance of a system operating with thermal energies at different levels of temperature.

The exergetic analysis finds the location and the magnitude of a malfunction that occurs inside the borders of a system and is capable to give solutions for improvement.

The exergy destruction associated with throttling is responsible for the lower exergetic efficiency of the $\mathrm{CO}_{2}$ system compared to the one that operates with $\mathrm{NH}_{3}$. For $\mathrm{CO}_{2}$ the lower is the throttling process the higher is the overall efficiency. All the attempts to reduce the exergy destructions in the gas heater or intermediary cooling processes have had no benefit as long as throttling has been increased.

The schematic in Fig. 2 with the incomplete intermediary cooling has the lower throttling and 

Cycles for Simultaneous Cooling and Heating

consequently the higher overall exergetic efficiency.

For $\mathrm{NH}_{3}$ the structural changes brought to the system in the aim to reduce the exergy destruction associated with the intermediary cooling and heat transfer in the condenser have improved the performance of the cooling and heating system.

\section{References}

[1] G. Lorenzen, Revival of carbon dioxide as a refrigerant, Int. J. Refrig. 17 (1994) 292-300.

[2] R. Yokoyama, T. Shimizu, K. Ito, K. Takemura, Influence of ambient temperatures on performance of a $\mathrm{CO}_{2}$ heat pump water heating system, Energy 32 (2007) 388-398.

[3] P. Neska, $\mathrm{CO}_{2}$ heat pump systems, Int. J. Refrig. 25 (2002) 421-427.

[4] R. Yumrutas, M. Kundus, M. Kanoglu, Exergy analysis of vapor compression refrigeration systems, Exergy, An Int. J. 2 (4) (2002) 266-272.
[5] E. Bilgen, H. Takahashi, Exergy analysis and experimental study of heat pump system, Exergy, An Int. J. 2 (4) (2002) 259-265.

[6] J. Sarkar, S. Bhattacharyya, M. R. Gopal, Transcritical $\mathrm{CO}_{2}$ heat pump systems: exergy analysis including heat transfer and fluid flow effects, Energy Conversion and Management 46 (2005) 2053-2067.

[7] A. Cavallini, P. Neksa, prospects for the return of $\mathrm{CO}_{2}$ as a refrigerant, Presented at CIAR 2001 [online], Buenos Aires, Argentina 2001, pp. 761-790, http://www. aafrio.org.ar/tema_congressos/ciar-2001/ciar_2001.htm.

[8] J.S. Brown, S.F. Yana-Motta, P.A. Domanski, Comparative analysis of automotive air conditioning systems operating with $\mathrm{CO}_{2}$ and R134a, Int. J. Refrig. 25 (2002) 19-32.

[9] A. Dobrovicescu, G. Tsatsaronis, Exergy destruction due to friction in heat exchangers-A refrigeration system case study, Presented at ECOS 2006 [online], National Technical University of Athens, Greece, July 12-14, http://www.ecos2006.ntua.gr. 